\title{
DO CONCEITO ROMANO DE IMPERIUM E SEUS DESVIOS JURIDICO-POLITICOS
}

\author{
ALOISIO SURGIK *
}

\section{SUMÁRIO}

1. Introdução . . . . . . . . . . . . . . . . . . . . 19

2. O Sentido Popular de Imperium na República Romana . . 20

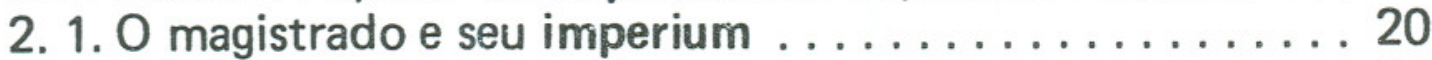

2. 2. Imperium e iurisdictio ................ 24

3. O Sentido Militar de Imperium a partir do advento do

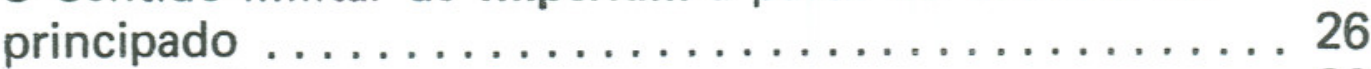

3. 1. Antecedentes .................... 26

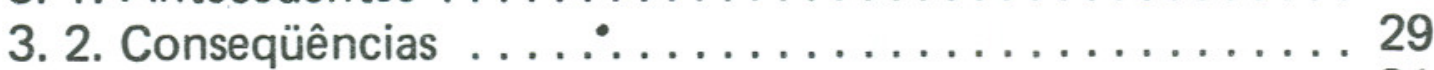

4. Conclusão . . . . . . . . . . . . . . . . . . . . . . 31

Notas . . . . . . . . . . . . . . . . . . . . . . . . . . . . 34

\section{INTRODUÇĀO}

Muitos são os vocábulos que, ao longo da História, sofreram desvios conceituais, chegando em alguns casos a passar por profundas deturpações, com as conseqüências óbvias daí resultantes nas etapas históricas subseqüentes.

A par das mutações semânticas, há que se levar em conta (e o pesquisador da História não pode ignorá-lo) que os próprios documentos históricos podem ter sofrido injunções de ordem política ou de outra ordem a comprometer-lhes, pelo menos em parte, a autenticidade, o que é sumamente necessário conhecer para a correta avaliação dos fatos históricos e, conseqüentemente, para o conhecimento da atualidade.

* Professor de Direito Romano da Pontif́́cia Universidade Católica do Paraná, da Faculdade de Direito de Curitiba e da Universidade Federal do Paraná. Doutor em Direito pela Universidade de São Paulo. Trabalho apresentado no V Congresso Latinoamericano de Derecho Romano (Lima). 
A longa trajetória histórica do Direito Romano abre hoje um campo vastíssimo de pesquisa, absolutamente indispensável para a verdadeira compreensão dos institutos jurídicos da atualidade.

Não bastasse a questão das interpolações existentes no Corpus luris Ciuilis, acerca das quais, aliás, a romanística do século passado chegou a ocupar-se até com certo exagero (1), convém levar em consideração as deformações históricas em que incorreram muitos autores (2).

Nas modestas limitações da presente explanação, focalizaremos alguns aspectos dos desvios de sentido com relação a imperium, especialmente na época de transição entre o regime republicano de Roma e o principado.

Por paradoxal que possa parecer e por mais que o vocábulo imperium nos suscite desde logo a idéia de dominação e autoritarismo, seu verdadeiro sentido de origem, na república romana, particularmente no âmbito processual, é de caráter nitidamente popular. Sua deturpação veio a ocorrer somente com o advento do principado e, de um modo especial, durante o império.

\section{O SENTIDO POPULAR DE IMPERIUM NA REPÜBLICA ROMANA}

\subsection{O magistrado e seu imperium}

No campo do processo civil romano, em estreita ligação com a iurisdictio, manifesta-se claramente o imperium, cuja própria razão de ser é a vontade popular.

Efetivamente, até a denominação de ordo iudiciorum priuatorum, que tão bem caracteriza o sistema processual da fase áurea da História do Direito Romano, nos dá a exata medida de seu sentido popular. Mesmo assim, ao contrário do que ocorre hoje em dia, o poder de mando dos magistrados é extremamente moderado, como observou JOSÉ LUIS MURGA: “EI papel que en todo este montaje ha de tener necesariamente la potestad publica o el imperium que los magistrados deban desempeñar y lo cual designamos con el nombre de jurisdición, aparece en el proceso romano tan diluido e inoperante que prácticamente puede decirse que, a diferencia de lo que ocurre hoy, en donde el 
aspecto público o constitucional aparece como lo más primordial, en el ordenamiento romano es al revés" (3).

Para bem entendermos a intervenção do magistrado romano em sua tarefa jurisdicional, que supõe a defesa organizada daquilo que hoje chamamos de direitos subjetivos, basta atentarmos para os três verbos clássicos - do, dico, addico - de que nos dão conta as fontes, principalmente as fontes literárias (tria uerba legitima) (4), expressas por vezes no infinitivo: dare, dicere, addicere.

\section{Eis como explica JOSÉ LUIS MURGA:}

Dare. Refere-se este verbo a um dar que se concretiza sempre pelo órgão jurisdicional com relação a alguém que pede. Este pedir e este dar podem ter sua concretização de modo definitivo e extrajudicial, como, por exemplo, dare tutorem, dare possessionem, etc., em atendimento ao pedido do interessado, ou com caráter transitório e processual, como seriam aqueles dare actionem, dare exceptionem, dare arbitros, dare iudicem, dare diem, dare tempus, etc., tão freqüentes na terminologia processual romana e onde o órgão jurisdicional é muito claramente manifesto em seu verdadeiro poder de mando, concedendo a ação, a exceção, nomeando os árbitros ou o juiz, ou, ainda, impondo um termo ou um prazo para as atuações, como verdadeira autoridade legitimada.

Dicere. É, sem dúvida alguma, o verbo mais importante e significativo da atividade jurisdicional do magistrado romano, a ponto de ser o verbo que dá nome à própria jurisdição, considerando-se que iurisdictio deriva de ius e dicere. Através do dicere, a magistratura pode concretizar e fixar a normatividade processual, dando viabilidade à tramitação dos litígios que considere necessários para a defesa dos direitos. Esta atividade "jusdicente" é a mais característica de todas, uma vez que a ela se deve exatamente o início e o estabelecimento dos pressupostos processuais do litígio.

Addicere. Trata-se na realidade de um verbo muito incolor, cuja significação supõe possivelmente uma intervenção jurisdicional mais modesta que o dare e o dicere. Já se afirmou que esta atuação do magistrado foi seguramente a mais antiga, a ponto de, em alguma época, a jurisdição se ter concretizado só no addicere do magistrado. Segundo FESTO, addicere equivaleria a aprovar simplesmente com a mera presença, qualquer atuação 
levada a efeito diante do órgão jurisdicional: addicere est proprie idem dicere et approbare dicendo (5).

Na observação de FRITZ SCHULTZ, a grande liberdade de que gozavam os magistrados sofreu consideráveis restrições, não pela lei, mas pelos próprios magistrados, através de seus editos (6). Antes do exercício de seu cargo, o magistrado jurisdicional costumava publicar um programa (edictum), em que fixava com muita precisão as circunstâncias em que outorgaria ou denegaria os iudicia (iudicium dabo; iudicium non dabo). Cada magistrado habitualmente adotava o edito de seu predecessor, com certas modificações e adições, e, desta sorte, gradualmente, se foi desenvolvendo um completo sistema de normas (ius honorarium, em contraste com o ius ciuile) que os magistrados propunham reiteradamente em seus editos.

A distinção que fez GAIO (7) entre iudicium legitimum e iudicium quod imperio continetur nada tem a ver com a diferença entre $o$ ius ciuile e o ius honorarium, esclarece FRITZ SCHULTZ (8). Iudicium legitimum era o iudicium que tinha lugar na cidade de Roma, ante um juiz singular, sendo, as partes e o juiz, cidadãos romanos. Na falta de algum destes requisitos, davase o iudicium quod imperio continetur.

Ainda que o conceito e a prática do imperium remonte à época da realeza - embora a etimologia da palavra seja muito incerta (9) - , seu verdadeiro sentido, já nos tempos mais remotos de Roma, era essencialmente popular, eis que, através da lex curiata de imperio, votada pelos comícios curiados, se conferia o imperium aos "magistrados superiores eleitos pelas assembléias", conforme observa muito bem JEAN GAUDEMET, ressaltando que o voto era "essencial para que os magistrados pudessem exercer suas funções" (10). Realmente, só o povo era o verdadeiro titular do poder, e o magistrado não obtinha sua autoridade (portanto, seu imperium), a não ser pela designação da assembléia: “c'est le peuple qui est le véritable titulaire du pouvoir et le magistrat n'obtient son autorité que par la désignation de l'assemblée"' (11).

O magistrado, a quem incumbia determinar previamente os princípios da instrução e julgamento das causas e garantir-lhes a execução, gozava do maior prestígio e autoridade, afirma BONJEAN, pois era eleito direta e imediatamente pelo povo (12).

A autoridade do magistrado aumentava na proporção de seu prestígio, e este dependia do desempenho de suas funções, razão pela qual era muito importante zelar pelo próprio nome, 
atendendo aos anseios e interesse do povo, de quem afinal dependia toda a carreira do magistrado. CÍCERO sintetizou muito bem a missão do magistrado: "genere personam ciuitatis, debereque elus dignitatem et decus sustinere, seruare leges, iura discribere, ea fidei suae commissa meminisse" (13) - Representar a cidade, devendo manter a sua dignidade e decoro, observar as leis, administrar a justiça, tendo em mente a confiança que Ihe foi depositada.

A investidura pelo voto popular é que realmente conferia ao magistrado o poder indispensável não só para tornar possível a execução das sentenças proferidas pelo iudex, como para garantir o exercício de todas as suas funções.

Não se trata, pois, de um poder discricionário, ou de um autoritarismo arbitrário. Era na realidade o próprio poder do povo que se delegava ao magistrado pelo voto das assembléias.

Assim, dois eram os poderes que caracterizavam as magistraturas romanas: a potestas e o imperium. Os magistrados inferiores tinham apenas a potestas, como afirma JEAN GAUDEMET (14), ao passo que os magistrados superiores (pretores, cônsules, assim como os magistrados investidos de magistraturas excepcionais), além da potestas, tinham também o imperium.

A potestas, segundo explicação do mesmo autor (15), designa mais geralmente qualquer forma de autoridade, tal como, no âmbito da família, por exemplo, o poder que tem o paterfamilias sobre os filhos (patria potestas).

Relativamente aos magistrados, a potestas implicava, em primeiro lugar, a capacidade de exprimir a vontade dos cidadãos sob forma de prescrições, obrigatórias enquanto durassem as funções do magistrado (ius edicendi), e, em segundo, a possibilidade de exercer certo poder de coerção (coercitio minor), que permitisse ao magistrado assegurar o cumprimento de suas prescrições.

Porém, o imperium, que conferia ao magistrado prerrogativas bem definidas (16), só se adquiria pelo voto, por força da lex curiata de imperio, sobre o que assim se expressa JEAN GAUDEMET: "La désignation du magistrat par le vote des comices centuriates ou tributes ne suffisait pas à l'investir du pouvoir. Celui-ci ne lui est acquis que par la lex curiata de imperio. Cette lex émane des comices curiates. Selon la tradition romaine, elle remonte à l'epoque royale"' (17).

No auge das conquistas populares, quando já a plebe havia conquistado o direito de eleger seu representante - o tribuno da 
plebe - , tal representante, não sendo propriamente um magistrado, nem podia, em princípio, ter o imperium. Apesar disto, seus poderes ultrapassavam muito o imperium dos magistrados, já que podia efetivamente paralisar a ação de qualquer magistrado (e igualmente de seus colegas tribunos), quer em oposição preventiva aos seus atos (prohibitio), quer cassando-lhes as decisões (intercessio), além dos outros poderes de que dispunha (18). Todos estes poderes eram, inquestionavelmente, de base popular.

\subsection{Imperium e iurisdictio}

As relações entre o imperium e a iurisdictio têm suscitado divergências entre os estudiosos, estabelecendo-se hoje, principaimente, duas teorias. A primeira identifica iurisdictio com imperium (imperium geral de que gozavam todos os magistrados). Esta teoria predomina entre os alemães, tendo como principais expoentes LEIFER e KASER. A segunda, de orientação italiana, liderada por LAURIA e, de certo modo, por GIOFFREDI (19), considera que a iurisdictio era ao invés, uma capacidade própria e específica dos magistrados que presidiam os litígios e que, portanto, nada ou muito pouco tinha a ver com o imperium ou poder geral da magistratura.

Ainda que ambas as posturas, tanto a alemã como a italiana, tenham um fundo comum de verdade, convence-nos mais a segunda. Efetivamente, a trajetória que marcou a história do pretor urbano é muito diferente da que se verificou com relação aos outros cargos públicos. Assim, enquanto a política republicana foi limitando gradativamente o imperium de todas as magistraturas, evitando assim, através de uma longa série de plebiscitos, qualquer tipo de excesso ou extralimitação no exercício do poder, a iurisdictio dos pretores, ao contrário, evidenciou um comportamento diferente, alargando cada vez mais o âmbito de sua competência, sobretudo a partir da lex Aebutia. Outro dado a comprovar que, pelo menos externamente, imperium e iurisdictio têm manifestações distintas, é que, enquanto o imperium admitia graus, daí a distinção que veio a se fazer entre imperium maius, imperium infinitum e imperium minor, a iurisdictio não os admitia, aparecendo sempre idêntica em todos os que a ostentavam. Ademais, segundo alguns textos, especialmente de ULPIANO e PAULO (20), parece realmente não haver qualquer dúvida de que a iurisdictio, pelo menos a ordinaria, nada teve a ver com o imperium, pelo menos em uma série de atuações ou medidas 
processuais mais especiais, a saber: os interdicta, as stipulationes praetoriae, as restitutiones in integrum e as missiones in possessionem, para as quais se reservou a qualificação de atos magis imperii quam iurisdictionis, que, segundo JOSÉ LUIS MURGA, é uma expressão "ambigua y poco feliz, tal vez quiera indicarnos no exactamente que esos cuatro actos procesales sean de naturaleza especial y distinta, sino simplesmente que en ellos se manifiesta más aquel aspecto de mando que constituia como la base genética de todo acto político" (21).

Seja como for, independentemente de se questionar a natureza da iurisdictio e do imperium, e seus vínculos de relação entre si, há que se frisar: ao longo da vida republicana de Roma, todo o poder concentrado na pessoa do magistrado era o poder do próprio povo que se delegava pelo voto das assembléias, conferindo-Ihe indiscutível legitimidade. Primeiramente, sem dúvida, com certo predomínio dos patrícios; posteriormente, porém, em virtude da lex Hortensia (287 antes da nossa era), com a mais ampla participação popular.

Cumpre reconhecer que a libertas, no sentido autenticamente romano, era aquela capaz de assegurar a autonomia da comunidade. Consistia na submissão voluntária às regras de conduta elaboradas em comum e encontrava sua garantia não tanto no plano individual, mas, principalmente, no equilíbrio de poderes que se combinavam e controlavam. Assim, JEAN GAUDEMET observou, referindo-se à "libertas" romana: "Cette liberté est celle de la cité autant que de ses membres. . . Elle consiste dans la soumission volontaire à la !oi délibéré en commun et trouve sa garantie moins dans le jeu de recours individuels qui sanctionneraient un droit subjectif à la liberté, que dans un équilibre des pouvoir que se combinent et se contrôlent" (22).

Dentro de todo este contexto é que se insere o imperium, evidentemente de caráter popular, na medida em que o magistrado recebia do povo tal poder e a ele devia prestar contas.

A deturpação conceitual e prática do imperium teve início quando, ao interesse comum (interesse da res publica), começou a sobrepor-se o interesse particular, estimulado pelas conquistas bélicas, que, em conseqüência de uma reforma militar feita por CAIO MÁRIO, tornaram os comandantes mais empenhados nas conquistas pessoais do que no interesse da res publica. 


\section{O SENTIDO MILITAR DE Imperium A PARTIR DO ADVENTO DO PRINCIPADO}

\subsection{Antecedentes}

O movimento que agitou a república romana desde o início do século I antes da nossa era, com a reforma da organização militar realizada por CAIO MÁRIO, por si só, prenunciava a queda da república.

Em 101 antes da nossa era, CAIO MÁRIO, percebendo as crescentes dificuldades no recrutamento de soldados para o exército romano, resultantes da proletarização da classe que fornecia seus maiores contigentes, patrocinou uma reforma, criando, para o ingresso nas fileiras, o sistema de voluntariado e introduzindo assim, amplamente, a mentalidade de um exército integrado por profissionais, não por cidadãos segundo seu nível econômico. Desta forma, a lealdade dos soldados, anteriormente voltada à pátria, passou a ser dirigida, de modo especial, aos comandantes. Estes possibilitavam a seus comandados a participação nos saques que acompanhavam as conquistas, proporcionando também aos veteranos desligados, terras em que pudessem estabelecer-se, reforçando desta maneira ainda mais a fidelidade dos comandos, que se sentiam estimulados a apoiar um comandante em campanhas promissoras em perspectivas de enriquecimento. Por sua vez, os comandantes, com tal reforma, ganharam grande projeção e fortalecimento, uma vez que, sentindo-se fortes e amparados com bem armadas legiões, logo se voltaram contra os interesses comuns da res publica, usando os exércitos como instrumentos de pressão, até mesmo contra o Senado, em proveito pessoal (23).

Assim, com a reforma da organização militar realizada por MÁRIO, deu-se a Roma exército à altura da conservação de seu vasto império, afirma JOSÉ CARLOS MOREIRA ALVES (24), mas, internamente, dela decorreu uma conseqüência funesta à república: o poder dos generais de livremente recrutar soldados e de receber o seu juramento vinculou estes àqueles, e, não, como anteriormente, os soldados a Roma.

SILA foi o primeiro a servir-se dessa arma poderosa - a fidelidade pessoal que lhe tributava o exército - para a dominação política interna. De 82 a 79 antes da nossa era, exerceu a ditadura (no sentido moderno de tirania), realizando várias reformas políticas, conforme suas conveniências, embora acabasse por 
abdicar espontaneamente do poder em 79, vindo a morrer um ano mais tarde.

Seguiram-se a este episódio as famosas façanhas de JÚLIO CÉSAR, cujo objetivo nítido era a implantação da monarquia absoluta (que, na realidade, veio a concretizar-se mais tarde com o dominato). Desrespeitando o Senado, que, em 51 antes da nossa era, Ihe negara a extensão de seu comando na Gália, logo em seguida, em 49, atravessou o Rubicão e invadiu a Itália, levando POMPEU e suas tropas a retirar-se da península, juntamente com magistrados republicanos e vários senadores, para Tessalônica.

Vencedor em Farsália (Grécia) e vendo consolidada a sua vitória com a derrota dos partidários de POMPEU, em Tapsus (África) e Munda (Espanha), CÉSAR, de 48 a 44 antes da nossa era, embora não reconhecido oficialmente como rei, agiu como se de fato o fora, a ponto de CÍCERO ter denominado este período de dominatus (25).

Sem dúvida, o poder de CÉSAR firmava-se basicamente no exército, nas dezenas de milhares de veteranos que haviam recebido terras nas províncias e na Itália, conforme afirmação de KOVALIOV, citando PLUTARCO (26). Qualquer oposição organizada seria imediatamente liquidada por ele, CÉSAR, cujo sustentáculo direto, como já dissemos, era o exército profissional surgido das guerras civis, em conseqüência da reforma militar de MÁRIO, anteriormente referida.

Preparou-se assim um terreno propício para o advento do principado, com o que se subverteria radicalmente o sentido de imperium, que, daí em diante, perdendo seu caráter popular, ganharia em definitivo um sentido acentuadamente militar.

De fato, como diz KOVALIOV (28), as linhas de formação do poder de OTAVIANO haviam sido já indicadas por seus antecessores, SILA e CÉSAR. Todavia, o cauto OTAVIANO tinha assimilado a lição de março de 44 antes da nossa era, que culminava com o assassinato de CÉSAR, e tratou de dar ao seu poder uma forma que parecesse mais "constitucional", mantendo na organização de seu governo, dentro do possível, elementos republicanos. Formalmente, a república, tão fortemente arraigada na consciência popular romana, continuou existindo, e OTAVIANO não deixou transparecer qualquer tendência monárquica. Ao contrário, o sistema que se concretizou sob seu poder, conhecido com o nome de "principado", passou por lenta formação, representando o fruto da vontade do imperador, porém, igual- 
mente, o resultado das circunstâncias e de uma real relação de forças. O ponto de partida foi a lei de PÜBLIO TÍCIO, de 43, pela qual se concediam aos triúnviros poderes ilimitados por cinco anos. Depois do acordo de Tarento, estes poderes foram prorrogados até 31 de dezembro de 33 . Por isto, em 10. de janeiro de 32, os poderes ditatoriais de OTAVIANO e de ANTONIO cessaram juridicamente. Contudo, eles não renunciaram, e, em 32, OTAVIANO continuava ainda a chamar-se "triúnviro". A bem da verdade, isto constituía uma usurpação, que se fazia necessário legitimar de qualquer modo. Uma tentativa de legitimação já tinha sido o juramento que, em 32, tanto OTAVIANO como ANTÓNIO haviam pedido às suas próprias tropas. Porém, a 10. de agosto de 30, com a morte de ANTÓNIO, sentiu-se OTAV!ANO, de fato, o único e absoluto senhor de Roma e de todos os seus domínios. No mesmo ano, o Senado, já ostensivamente subserviente a OTAVIANO, confirmou-lhe estes poderes, ampliando-os. Em 29, OTAVIANO regressou a Roma e celebrou um grande triunfo. Nesta ocasião, o título de "imperador", que usava desde alguns anos atrás, porém por sua conta, foi-lhe atribuído oficialmente (como havia ocorrido anteriormente com CÉSAR) em nome pessoal (praenomen). Em 28, foi-lhe atribuído o título de princeps senatus (o primeiro, o principal do Senado).

Em 13 de janeiro de 27, surge o principado. OTAVIANO, diante do Senado, habilidosamente, depôs seus poderes extraordinários, declarando retornar à condição de simples cidadão romano. O Senado, porém, Ihe suplicou que reconsiderasse 0 ato, ao que OTAVIANO acedeu, sob duas condições: $1^{a}$., que as províncias romanas se repartissem entre o Senado (províncias senatoriais) pacificadas e, portanto, carecedoras de exército nelas sediado, e ele (províncias imperais, conturbadas por agitações e demandando, conseqüentemente, a presença de tropas); 2a., que o exercício de suas funções extraordinárias se limitasse, no tempo, a dez anos (29).

Em 23, OTAVIANO (a quem o Senado, dias depois da sessão de 13 de janeiro de 27, tinha outorgado o título de AUGUSTO) renunciou ao consulado que vinha exercendo ininterruptamente desde 31 . Com esta renúncia - explica MOREIRA ALVES (30) - , ele recebeu o proconsulado sem as limitações existentes na república, pois passou a exercer esta magistratura em toda a extensão do território romano.

Consolidava-se assim AUGUSTO na posição de princeps: com o proconsulado, tinha o comando geral dos exércitos roma- 
nos; com a tribunicia potestas, a inviolabilidade pessoal e o veto às decisões dos magistrados republicanos.

Desta forma, observa JEAN GAUDEMET (31), AUGUSTO tem o poder tribunício sem ser tribuno (e ainda sem estar exposto à intercessio de um colega), e o imperium proconsular sem ser procônsul de uma província (o que, por si só, descarta qualquer limitação territorial). Por outro lado, ele dispõe de poderes e cumula-os sem limite de tempo.

O conjunto de poderes tão essenciais, concentradas em um único titular, sem outorga popular, transformava o regime republicano em um regime ostensivamente autoritário, imperial.

Assim, o imperium, outrora outorgado aos magistrados romanos através do voto popular, expande-se pouco a pouco, assumindo tipicamente fisionomia imperialista, que é, antes de mais nada, militar, tendo como conseqüência, o imperialismo econômico, na expressão de JEAN GAUDEMET: “Cet imperialisme fut d'ailleurs avant tout militaire. L'imperialisme économique n'en fut qu'une consequence" (32).

É o regime pessoal que se sobrepõe ao púpular, como resultado do fenômeno das conquistas bélicas, consoante afirmação de LÉON HOMO: "Le régime personal est né de causes lointaines et de nécessités profondes. On peut les résumer toutes d'un mot: la conquête" (33). O imperador deve o título de imperator à necessidade militar do império. "L'ordenamento militare augusteo è quindi l'immagine più precisa del modo in cui Augusto ha concepito le sue funzione", observa MAZZARINO (34).

Pode afirmar-se, pois, que, a partir desta época, as legiões constituíram a espinha dorsal do exército e o exército a espinha dorsal do regime imperial.

\subsection{Conseqüências}

Dispondo dos mais amplos poderes e intitulando-se imperator, após a batalha de Actium (em 29 antes da nossa era), considerado este título como praenomen hereditário, por ser OTAVIANO filho adotivo de JÚLIO CÉSAR, o poder imperial de AUGUSTO foi consolidando-se cada vez mais e, posteriormente, estendendo-se a seus sucessores, em cuja solenidade de proclamação do praenomen de imperator e a intervenção do exército se manifesta mais como uma usurpação de poderes do que como procedimento legal, conforme observação de VILLANUEVA: "Dopo Tiberio l'insieme delle attribuzioni propriamente dette 
del potere imperiale venne conferito a vita, e con due atti distinti e sucessivi, cioè: 10. II conferimento del praenomen di imperator da parte del Senato; apparendo l'intervento dell'esercito nella proclamazione piuttosto quale un'usurpazione di potere che come una procedura legale, al pari dell'intervento del Senato. . . 20. La delegazione della potestas tribunicia a vita e senza limite di luogo, superiore a quella dei tribuni plebis" (35).

Cumpre recordar que, no século I, o imperador consideravase apenas o primeiro dos magistrados (princeps), título não oficial e que mais tarde mudou de sentido, identificando-se com imperator de Roma, cujo governo, aliás, era dividido com o Senado. Ainda que inviolável em conseqüência da potestas tribunicia e, em certo sentido, sagrado (augustus), nem por isso o imperador deixava de estar subordinado às leis. Todavia, a repartição de poderes com o Senado, na realidade, desde o início, nunca existiu, uma vez que o imperador açambarcava de fato um poder muito mais preponderante. Tal preponderância transformou-se pouco a pouco em superioridade absoluta, e a diarquia em monarquia. Se bem que a monarquia absoluta só viesse a consolidar-se após DIOCLECIANO, a preparação de tal transformação já havia tido início muito antes.

Depois do século III, o imperador passou a considerar-se superior às leis (legibus solutus), com poderes ilimitados e plenos (36), recebendo nos documentos oficiais o título de dominus e, maị tarde, depois de AURÉLIO, os de dominus et deus. Sua pessoa revestiu-se de majestade sagrada e divina, que se exteriorizava na púrpura (introduzida por DIOCLECIANO), no diadema e no nimbus, adotados por CONSTANTINO, e na cerimônia da adoração (37).

De resto, tudo o que agradasse ao príncipe tinha força de lei, como se tal poder tivesse sido conferido pelo povo: "Quod principi placuit legis habet uigorem, utpote cum lege regia, quae de imperio eius lata est, populus ei et in eum omne suum imperium et potestatem conferat" (38).

Já sob DIOCLECIANO e seus sucessores, criaram-se Césares escolhidos exclusivamente pelo próprio imperador reinante, sendo apenas confirmados pelo Senado, que, sem qualquer iniciativa própria, limitava-se a homologar a vontade imperial, registrando simplesmente o fato consumado sem sua participação. No fundo, a escolha era do exército, esclarece VILLANUEVA: “Benchè gli imperiali predecessori venissero appellati parentes, I'impero non fu mai ereditario; ma l'imperatore continuò ad essere nominato, 
in apparenza, dal Senato, in realtà, dal esercito, ovvero per designazione dei predecessori per adozione e conferimento dei titoli di Caesar e di Augustus" (37).

Sintomaticamente, a transição histórica que marca, no âmbito político, o término do regime republicano e o início do principado, também acarreta, no âmbito jurídico, o desvio conceitual do poder de imperium, cujo caráter, eminentemente popular durante a república, subverte-se a partir do principado, centraizando-se na pessoa do imperador e assumindo um sentido caracteristicamente militar. Desta forma, projeta-se para os séculos subseqüentes.

\section{CONCLUSĀO}

Sem que se faça necessário aqui discutir sobre qual teria sido a melhor experiência jurídico-política para os romanos (a popular - res publica - , ou a militar - imperium), os fatos, por si mesmos, falam muito mais eloqüentemente do que quaisquer argumentos.

A derrocada do regime imperial romano é um fato histórico inconteste.

Em 476, cai o Império romano do Ocidente. De certa forma, teve continuação, também para a Igreja, no Império Bizantino (Império do Oriente ou Baixo Império), porém, cada vez mais debilitado, acabou por sucumbir em 1453.

Entrementes, em Roma, na histórica noite de Natal de 888, o papa LEĀO III coroava CARĹOS MAGNO, proferindo as memoráveis palavras: "Carolo piissimo, Augusto, a Deo coronato, magno pacifico imperatori uita et uictoria", acrescentando-se a este ato a aclamação do povo aos Césares.

$\mathrm{O}$ império de CARLOS MAGNO denominou-se romano. $\mathrm{E}$, na verdade, o era sob muitos aspectos (39). Porém, dizendo-se romano, na realidade, era também, de certa forma, eclesiástico, por se constituir uma verdadeira coluna de sustentação do poder da Igreja.

Efetivamente, o Sacro Império Romano foi criado com uma finalidade claramente político-religiosa, com profundas conseqüências na sedimentação dos pilares da civilização ocidental cristã.

"A experiência dos grandes impérios antigos deixou uma imagem que se tornou quase um arquétipo para os povos posteriores", afirma NELSON SALDANHA (40). 
Sem dúvida, a influência dos moldes romanos permaneceu sempre e se renovou durante a Renascença. Assim, CARLOS V, monarca da Espanha e da Alemanha, pretendeu reviver a idéia de império como uma totalidade, com pretensão universal.

O Império otomano, fundado por força de armas sobre as ruínas do velho Império romano bizantino, tendo por cabeça o sultão, que foi ao mesmo tempo imperador e chefe religioso, tomou a forma da mais absoluta monarquia, transmissível em linha masculina por ordem de primogenitura (41).

Sem mencionarmos outros tipos de regimes imperiais ao longo da História, cumpre salientar desde logo que os desvios conceituais de imperium, que tiveram início com o advento do principado, sob AUGUSTO, sofreram total degenerescência no curso da História, culminando com o imperialismo econômico dos nossos dias.

Como bem salientou NELSON SALDANHA, "o termo imperialismo, utilizado pelos sociólogos e economistas, designa no século $\mathrm{XX}$ sistemas de dominação econômica. Esta dominação pode eventualmente completar-se com formas de ocupação militar e de pressão política, mas ela é basicamente caracterizada pela exploração econômica" (42).

Nesta perspectiva, na medida em que as "fronteiras nacionais" não passam de marcos para os deslocamentos dos fatores e produtos (43) e, conseqüentemente, a troca desigual do comércio entre as nações acentua cada vez mais a dependência e a miséria dos países pobres, a internacionalização do capital, hoje, também reduz nações a meros espaços físico-econômicos.

$O$ século $X X$ assinala a passagem do velho capitalismo para o novo; da dominação do capital em geral para a dominação do capital financeiro. Este, concentrado em poucas mãos e gozando do monopólio efetivo, consolida a dominação da oligarquia financeira e impõe a toda uma sociedade o controle de suas fontes de matérias-primas e o tributo em proveito dos monopolistas (44). É a partilha do mundo segundo o capital e segundo a força.

Importa analisar o presente numa retrospectiva crítica ao passado.

A transição da república romana para o principado desvia o conceito de imperium, subvertendo-lhe o sentido jurídico-popular e imprimindo-lhe caráter político militar.

Hoje, no dizer de RICARDO ABROMOVAY, a terminologia militar vem invadindo sintomaticamente todas as áreas da vida social. 
Até mesmo o que há de mais vital para a sobrevivência da espécie humana, como é o alimento, constitui hoje arma de dominação, a ponto de as Nações Unidas terem como um de seus objetivos o estabelecimento no mundo da segurança alimentar. “Um punhado de países ricos exerce tal controle sobre a produção e a comercialização de cereais que lhes permite reduzir os outros povos à sua mercê. $\mathrm{O}$ alimento hoje é uma arma de poder, isto é, de imposição de vontades e interesses . . . um dos fundamentos da dependência econômica e política dos países pobres e, portanto, um importante instrumento de dominação imperialista" (45).

É claro que não podemos debitar este tipo de imperialismo à herança histórica romana. Ao contrário, Roma tem muito a ensinar-nos, principalmente no que tange à participação e à conscientização jurídica e política. Basta desvendarmos os arcanos de seus inesgotáveis tesouros de lições históricas.

O tema em foco sugere ao estudioso de hoje um retorno ao passado, para redimensionar o conceito de imperium, restituindoIhe o autêntico sentido jurídico-popular e com isto, contribuindo para que, no futuro, o "direito da força" dê lugar à força do direito. 


\section{NOTAS}

1. Haja visto o livro escrito por KALB e significativamente intitulado: $A$ caça às interpolações no Digesto (Die Jagd nach Interpolationen in den Digesten), publicado em 1897.

2. Veja-se, por exemplo, a propósito dos Comentários de CÉSAR, MICHEL RAMBAUD, L'art de la deformation historique dans les Comentaires de César, Paris, 1966.

3. JOSÉ LUIS MURGA GENER, Derecho romano clássico - II; El proceso, Saragoza, 1980 , p. 30.

4. VARRÃO, De lingua latina, 6, 30; MACRÓBIO, Saturnalia, 1, 16, 14; OVIDIO, Fasti, 1, 47, ss.; SÊNECA, De tranquilitate animi, 3; Cf. JOSÉ LUIS MURGA, op. cit., p. 37; P. NOAILLES, Du droit sacré au droit civil, Paris, 1949, p. 284 ss.

5. FESTO, De uerborum significatione, 13; Cf. JOSÉ LUIS MURGA, op. cit., p. 38.

6. FRITZ SCHULTZ, Derecho romano clássico, trad. José Santa Cruz Teigeiro, Barcelona, 1960, p. 17.

7. Gai, 4, 103-9.

8. Op. cit., p. 17.

9. Cf. JEAN GAUDEMET, Institutions de l'antiquité, Paris, 1967, p. 207.

10. Idem, ibidem.

11. Idem, p. 330 .

12. L. B. BONJEAN, Traité des actions chez les romains, Paris, 1845, Tomo I, p. 36.

13. CÍCERO, De officiis, 1, 34, 124.

14. Op. cit., p. 330. Quando se fala em magistrados inferiores e superiores, não se quer dizer que houvesse subordinação hierárquica entre eles; havia apenas diversificação de funções. Na realidade, cada magistrado era plenamente autônomo em sua respectiva área de jurisdição.

15. Idem, p. 331 .

16. Sobre as atribuições dos magistrados, v. T. MONNSEN, Droit public (trad. fr.), I, $135,240$.

17. Op. cit., p. 336 .

18. Idem, p. 296.

19. LEIFER expõe principalmente sua teoria unitária (iurisdictio $=$ imperium) em sua obra Die Einheit des Gewaltgedemkeus im romischen Staatsrecht, Junchenn, 1914, tendo de certo modo como seguidor ROSEMBERG, em Paulys Realency. clopadie der classichen Alfertumswissenschaft (ed. Pauly Wissowa, Kroll, Mittethans, Ziegler, Stuttgard), Imperium. Mais importante é KASER, Das romische Zivilprozessrecht, München, 1966 , p. 26 ss. A corrente italiana é expressa por LAURIA, Iurisdictio, em Studi in onore di Pietro Bonfante - 1929-30, 2, p. 481, assim como por GIOFFREDI, Contributi allo studio del processo civile romano, Milano, 1947, podendo também ser colocado nesta linha DE MARTINO, La giurisdizione nel diritto romano, Padova, 1937, apud JOSÉ LUIS MURGA GENER, op. cit., p. 40.

20. Cf. D. $50,1,26 ; 2,1,4 ; 3,1,10 ; 39,2,1 ; 4,3,4,1$.

21. Op. cit., p. 46.

22. Op. cit., p. 357. Note-se que a concepção do liberalismo do século XVIII é totalmente diferente da concepção romana.

23. SÉRGIO DE SÁ MENDES, Direito romano resumido, Rio de Janeiro, 1981, p. 39.

24. JOSÉ CARLOS MOREIRA ALVES, Direito romano, Rio de Janeiro, 1978, p. 37.

25. CÍCERO, Epistolae ad familiares, 4, 8, 2. Cf. JOSÉ CARLOS MOREIRA ALVES, op. cit., p. 38.

26. PlUTARCO, C. Caesar, LVI, Cf. S. I. KOVAlIOV, Historia de Roma, trad. Marcelo Ravoni, T. 2, Buenos Aires, 1964, p. 118.

27. PREVOST, Les adoptions politiques à Rome sous la république et leprincipat, Paris, 1949; W. SCHMITTHENNER, Oktavian und das Test. Caesars, München, 
1952; M. LEMOSSE, L'adoption d'Octave, St. Albertario I (1953), 369-395; H. HENNE, $A$ propos du testament de César, Mél. Lévy-Bruhl (1958) 141-152; DELL'ORO, Confirmatio adoptionis non iure factae, Labeo V (1959) 15-16; J. PAOLI, Le test. calatis comitiis et l'adrogation d'Otave, St. Betti III (1962) 529-563; FR. DE MARTINO, Storia, IV, 1, 52-55.

28. Op. cit., p. 131.

29. J. C. MOREIRA ALVES, op. cit., p. 38.

30. Idem, p. 39.

31. Op. cit., p. 456.

32. Op. cit., p. 369.

33. LËON HOMO, Les institutions politiques romaines, Paris, 1950, p. 243.

34. SANTO MAZZARINO, L'impero romano, Roma, Bari, 1973, p. 84.

35. LUIGI SICILIANO VILlANUEVA, "Impero, imperium", in Digesto Italiano, XIII, p. 75.

36. D. $1,3,31$.

37. L. S. VILLANUEVA, op. cit., p. 76.

38. D. $1,1,4$.

39. Cf. L. S. VILlANUEVA, op. cit., p. 77.

40. Cf. NELSON SALDANHA, "Império", in Enciclopéia Saraiva do direito, vol. 42, São Paulo, 1977, p. 310.

41. L. S. VILLANUEVA, op. cit., p. 82.

42. NELSON SALDANHA, op. cit., p. 311.

43. V. RABAH BENAKOUCHE, O que é capital internacional, Ed. Brasiliense, 1984, p. 14.

44. v. AFRÂNIO MENDES CATANI, $O$ que é imperialismo, Ed. Brasiliense, 1981, p. 26 ss.

45. v. RICARDO ABRAMOVAY, O que é fome, Ed. Brasiliense, 1983, p. 101. 